\title{
Dissertation to Journal Article: A Systematic Approach
}

\author{
Brychan Thomas and Heather Skinner \\ Glamorgan Business School, Faculty of Business and Society, University of Glamorgan, Pontypridd CF37 1DL, UK \\ Correspondence should be addressed to Brychan Thomas, bcthomas@glam.ac.uk
}

Received 21 March 2012; Revised 6 June 2012; Accepted 6 June 2012

Academic Editor: Stephen P. Heyneman

Copyright ( $) 2012$ B. Thomas and H. Skinner. This is an open access article distributed under the Creative Commons Attribution License, which permits unrestricted use, distribution, and reproduction in any medium, provided the original work is properly cited.

\begin{abstract}
The aim of the paper is to elucidate a systematic approach to convert a Masters dissertation into a journal article. This approach has involved a fundamental thematic review of the literature concerning the conversion of dissertations into journal articles. From these sources pertinent approaches, processes, lessons, and guidance have been noted and analysed. By undertaking this distillation of relevant material, to enable the efficient conversion of dissertations into journal articles, appropriate procedures and conclusions have been compiled. Findings present current thinking on the conversion of a dissertation into a journal paper in terms of how dissertations differ from journal articles, reframing for publication, rethinking the material, trimming the length, time taken to rewrite the material, specific lessons, and adapting for publication. Recommendations provided in the paper will enable staff to take this course of action when developing their publication portfolio to become more research active and to make an important contribution to the publication output of their department/school/faculty, especially with regard to assessment exercises such as the Research Excellence Framework. The value of the paper is that by following appropriate approaches, processes, and procedures it is possible to convert a good dissertation into a ranked journal article.
\end{abstract}

\section{Introduction}

This paper provides a "toolkit" that can be used by academics as part of a systematic approach to convert a dissertation into a journal article. The paper considers a number of factors, and these include the quality of the dissertation, the authorship involved, journal ranking and selection, how dissertations differ from journal articles, reframing for publication, turning the dissertation into a publication, contents, seven rules, and conclusions.

The extant literature describes a number of approaches to convert dissertations into journal articles including revising dissertation chapters for publication as journal articles [1], converting a dissertation into a journal article [2], turning a dissertation into a publication, writing a journal article in twelve weeks [3], from qualitative dissertation to quality articles [4], and adapting a dissertation publication $[5,6]$.

Thirty years ago it was fairly easy to publish, but, in recent times with the Research Assessment Exercise (RAE), now the Research Excellence Framework (REF), it has become more difficult. This has resulted in more competition and rigorous processes. In response to this academic staff need to follow a personal publication programme as outlined in this paper in the publication "toolkit" in order to develop good dissertations into rated journal articles. As a consequence the RAE, now the REF, has created greater competition between universities and academic staff for national recognition and research-related income resulting in research becoming an important activity in the traditional teaching led universities [7]. Many academics undertake research to support their teaching and publishing articles in journals that is a useful way to gain recognition. This may not be an end in itself but is important to gain internal and external recognition. Many academic posts prioritise applicants with an established or future research profile.

Academic staff will have varied experience of publishing in journals ranging from little to considerable experience. There are a number of ways to develop journal papers, and these include the following:

(i) coauthoring and developing conference papers,

(ii) writing up research project results as journal papers,

(iii) using a masters dissertation to develop a journal paper, 


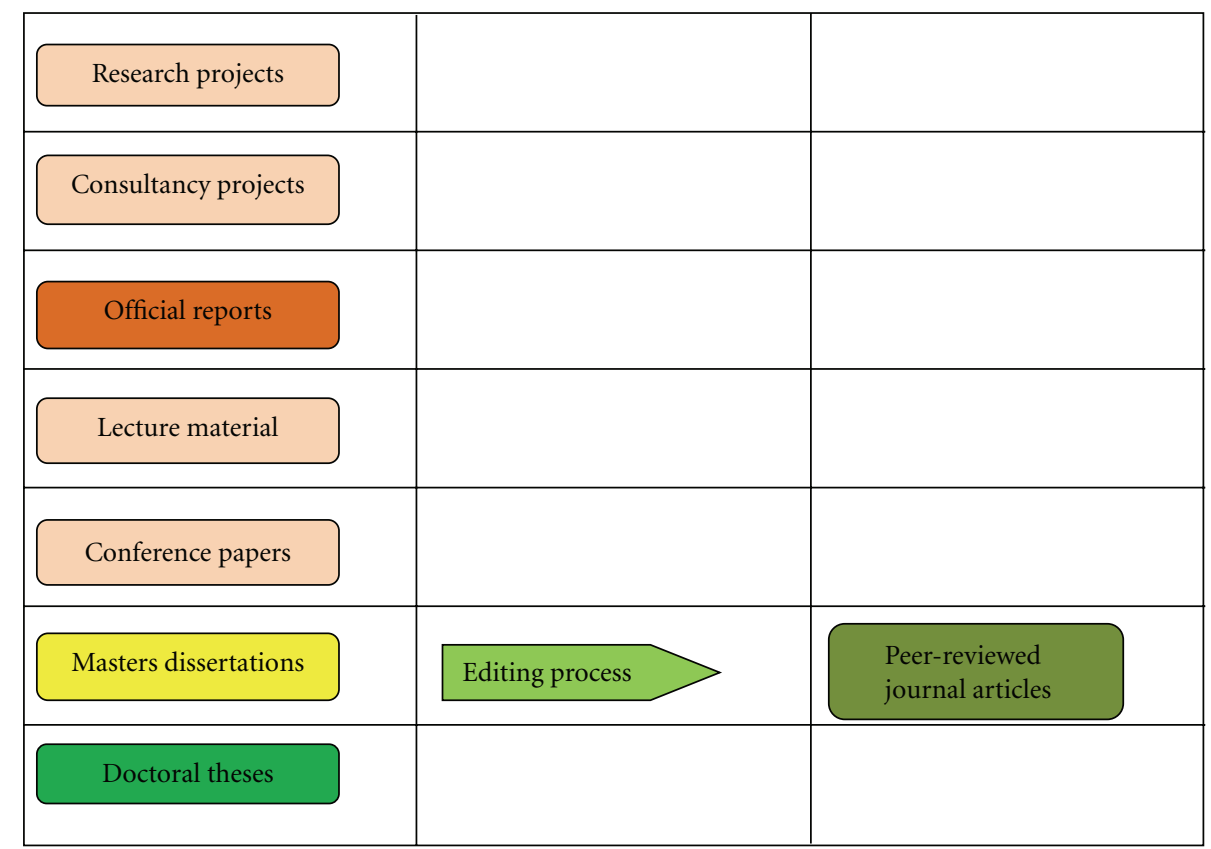

Figure 1: Sources of journal articles.

(iv) assisting an established author on a project, and

(v) coauthorship with another author including established authors.

The sources of journal articles are shown in Figure 1 with the emphasis placed on masters dissertations involving the editing process leading to publication in peer-reviewed journals.

If a dissertation is the right quality and appropriate to a particular journal then a submission can be made. There are a number of factors involved and ways of doing this including the publication "toolkit" and the personal publication programme. An ideal situation for a less-experienced academic, in terms of publishing, is to have a "mentor" or more experienced colleague who can offer advice on developments within a shared subject area and who may offer to coauthor. To develop a research journal publications profile there are a number of factors that have to be taken into consideration, and these include the conversion of conference papers into journal article papers, journal productivity, the publication process model, and criteria for developing a journal paper. First, there is the conversion factor for converting conference papers into journal papers (1). If this is one or greater, it is a positive factor and shows that the author has successfully taken papers from conference to journal.

\section{Conversion Factor.}

$$
\frac{N_{\mathrm{JP}}}{N_{\mathrm{CP}}}=1
$$

where $N_{\mathrm{JP}}$ - number of peer-review journal article papers, and $N_{\mathrm{CP}}$-number of peer-reviewed conference papers.

For an academic with 91 refereed conference papers and 90 refereed journal papers the conversion factor will equal
TABLE 1: Journal productivity.

\begin{tabular}{lcc}
\hline Year & 2012 & 2013 \\
\hline Journal paper target & 2 & 2 \\
\hline
\end{tabular}

0.989 and can be considered to show good conversion. For an academic who has presented 30 refereed conference papers and 10 journal papers this gives a figure of 0.33 and shows low conversion. By developing dissertations into journal articles it is possible to improve journal paper output. In relation to this journal productivity needs to be taken into account. In terms of the forthcoming REF there is a need for four academic journal papers by November 2013, and this can be achieved by developing four dissertations into journal papers during 2012 and 2013 (Table 1).

The journal paper target is two in 2012 and two in 2013 with ABS 1 or 2 ranking. To achieve this the publication process model can be followed when converting a dissertation into a journal article (Figure 2).

Factors taken into account are the quality of the dissertation, the authorship involved, selection of appropriate journals, trimming the dissertation to the correct length for the journal, and developing the draft and submission to the target journal. The criteria involved in developing a dissertation into a journal paper are shown in Table 2.

\section{Quality of the Dissertation}

The quality of the dissertation is an important initial factor. If the dissertation has not received a good mark, it will probably not evolve into a ranked journal article. Table 3 shows the quality of a dissertation based on the percentage and award level. In terms of a dissertation being the right quality to 
TABLE 2: Criteria for developing a dissertation into a journal paper.

\begin{tabular}{lll}
\hline Section & Title & Content \\
\hline 1 & Introduction & Issue under investigation, statement of the aims and objectives, and reasoned rationale. \\
\hline 3 & Literature review & Comprehensive investigation of secondary sources and conceptual framework. \\
\hline 4 & Research methodology & $\begin{array}{l}\text { Philosophical underpinnings, selection, and application of research methods appropriate to meth- } \\
\text { odology. }\end{array}$ \\
\hline 5 & Discussion & Presentation of primary data that reflects theoretical framework. \\
6 & Conclusion & $\begin{array}{l}\text { Key issues from the primary and secondary research investigated which are focused towards responding } \\
\text { to the aims and objectives. Consideration of the recommendations, research limitations, future research, } \\
\text { and policy implications. }\end{array}$ \\
\hline
\end{tabular}

Based on the marking criteria for dissertations, University of Glamorgan.

\begin{tabular}{|c|c|c|c|c|c|}
\hline $\begin{array}{c}\text { Dissertation } \\
\text { selection }\end{array}$ & Authors & Journals & $\begin{array}{c}\text { Reduction in } \\
\text { length }\end{array}$ & Editing & Submission \\
\hline Quality & $\rightarrow$ Authorship & $\begin{array}{c}\text { Selecting } \\
\text { journal }\end{array}$ & Trimming & Draft & $\begin{array}{c}\text { Target } \\
\text { journal }\end{array}$ \\
\hline
\end{tabular}

FIgUre 2: Publication process model.

TABLe 3: Quality of dissertation.

\begin{tabular}{lc}
\hline Percentage & Award \\
\hline $70+\%$ & Distinction \\
$60-69 \%$ & Merit \\
$40-59 \%$ & Pass \\
\hline
\end{tabular}

form the basis of a journal paper a pass mark of 40-59\% will probably not provide a dissertation that can be used. There is a need to focus on dissertations of at least 60-69\% (merit) and especially $70 \%+$ (distinction) to have the basis for a good refereed journal paper.

Choosing appropriate dissertations will involve a process of elimination to sift out those that are not the right quality and to identify appropriate subject areas of interest to the author and journals.

\section{Authorship}

The basis of the writing team will be formed by the dissertation supervisor and the student. If the supervisor is confident of developing a dissertation, with the help of the student providing additional information, a two coauthor paper should suffice. Often a supervisor wants to include an additional academic who has publishing experience to help with the development of the paper (Table 4). This can be of considerable help to the dissertation supervisor who might have a heavy teaching load and little time to work on a paper or wants a member of staff with publishing experience to craft the paper for publication and who has expert knowledge of the publication process with certain journals through having experience of being on editorial advisory boards.

Table 4 shows a typical listing of authors for a peerreviewed journal with the lead author being the dissertation student, or supervisor, the second author the dissertation supervisor, student, or second academic who has publishing experience, and the third author the second academic or the dissertation student. This can be alternated if the second academic has to undertake work developing the paper resulting in being the second author (Table 4: author listing C). There may be the need to have additional authors if further expertise is required in terms of data analysis or knowledge of the subject area. The author listing will depend on the preferences of the authors and based upon the requirements of the work the author positions will become clear.

\section{Journals: Ranking and Selection}

Peer-reviewed journals are published by established publishing houses. A good overview of journals is provided by the Writers' and Artists' Yearbook and the Writer's Handbook (both available from high street book stores). The lists provided in these include recognised publishers such as the Oxford University Press, Cambridge University Press, SAGE, CARFAX, Routledge, and Blackwell. In terms of the subject area of Business and Management the definitive guide to journal ranking and selection is the Association of Business Schools (ABSs) tables for the United Kingdom which are an amalgam of previous ranking systems (Table 5). All peerreviewed journals undertake double or triple blind peerreview refereeing, with the editor acting as a "gatekeeper." In order to have insight into the review process it can be useful to offer to act as an official reviewer or to be considered for an editorial review board. It is sensible to identify appropriate journals for dissertation material before starting to develop a paper, and this can be achieved by compiling a list with a first, second, and third choice. 
TABLE 4: Authorship.

\begin{tabular}{llll}
\hline & Author listing A & Author listing B & Author listing C \\
\hline Lead author & Dissertation student & Dissertation supervisor & Dissertation supervisor \\
Second author & Dissertation supervisor & Dissertation student & Second academic \\
Third author & Second academic & Second academic & Dissertation student \\
\hline
\end{tabular}

TABLE 5: Journals: ranking and selection.

\begin{tabular}{lcc}
\hline ABS ranking & Range & Ranking consideration \\
\hline ABS 4 & & \\
ABS 3 & & Target \\
ABS 2 & $\uparrow$ & Ranking \\
ABS 1 & $\downarrow$ & \\
ABS 0 & & \\
\hline
\end{tabular}

In terms of ranking and journal selection for dissertations the most appropriate ABS rankings are probably ABS 1 for a dissertation of merit standard and ABS 2 for a dissertation with a distinction. This may vary between subject areas and according to the standard of marking.

\section{How Dissertations Differ from Journal Articles}

Dissertations differ from journal articles in a number of ways in terms of the length of the work, abstract length, literature review, research methodology, research findings and analysis, discussion, references, and appendices (Table 6). A dissertation will have an abstract from 120 to 350 words whereas a journal abstract will be in the range from 150 to 250 words. A literature review in a journal article will be shorter than a dissertation and will be more focused. The research methodology in a journal article will describe the methods used and will not include extensive discussion of the research approach and philosophy found in a dissertation.

The research findings and analysis in a journal article will provide the main findings and analysis of the research and will not report all the results as found in a dissertation. The discussion section in a dissertation will be longer than in a journal manuscript submission. Only references cited in the text will be included in the journal article reference list. Space and content requirements will limit the use of appendices in journal articles although according to the journal's and editor's requirements some journals have research instruments included as appendices such as the questionnaire distributed, questions asked at interviews, or themes discussed at focus groups.

\section{Reframing for Journal Publication}

To reframe a dissertation for a journal article requires a tight theoretical framework, a succinct literature review, a controlled presentation of the methodology, and concise discussion of the results. Since articles evolved from dissertations will be shorter, there is a need to trim the length of the dissertation (Table 7). The process of trimming involves selecting and rewriting instead of cutting and pasting. For a journal article extraneous material must be removed, and substance needs to be preserved.

"Pit falls" when trimming a dissertation are as follows:

(i) inconsistencies with references-dates wrong in the text and references missing from the bibliography,

(ii) the use of "as cited in" with references in the text,

(iii) plagiarism of material,

(iv) "Tell tale" signs that the material has come from a Masters' dissertation, and

(v) limited data and analysis.

Table 7 illustrates reasons for trimming in relation to journal paper development. These include the research question (narrow the focus of research questions), results (only include results that are directly relevant to the research paper), presentation (adjust according to journal requirements), conventions (follow the journal format), references (include those appropriate), writing style (ensure style in accordance with journal style), interpretation of data (be realistic), and undertake careful conversion (ensure that care is taken when converting).

\section{Turning the Dissertation into a Publication: A Systematic Approach}

When developing dissertations into journal publications, papers need to be written according to the journals' rules which are published and included on journal websites. Following the introduction of the RAE there were many unprepared papers submitted to journals which resulted in a rejection rate of $80 \%$ by some journals. This rate fell but has built up before later RAEs, and this will be the same for the current REF. When identifying journals it is important to look through previous issues in the journal archive web page noting factors such as the word limit of papers, overall format, and referencing style. It is also useful to contact the editor before submitting a paper to gain views on whether the journal would be interested in the paper. Additionally, look out for special issues which a paper would easily "fit."

A systematic approach is provided in Table 8 for turning dissertations into journal papers, and this follows fifteen stages or steps to follow from planning and starting the article to sending, receiving the reviewers' comments from the journal, and responding to these.

When the decision from the journal editor, based upon the reviews of the referees, is received, the recommendation will be to accept the paper, accept subject to minor revision, 
TABLE 6: How dissertations differ from journal articles.

\begin{tabular}{ll}
\hline Feature & Difference \\
\hline Abstract length & $\begin{array}{l}\text { A typical dissertation will have an abstract of } 120 \text { to } 350 \text { words whereas an abstract for a journal will } \\
\text { usually be in the range } 150 \text { to } 250 \text { words. }\end{array}$ \\
\hline Introduction & The introduction in a dissertation is similar to that in a journal article. \\
\hline Literature review & $\begin{array}{l}\text { A literature review in a journal article will be much shorter than a dissertation and will be far more } \\
\text { focused. }\end{array}$ \\
\hline Research methodology & $\begin{array}{l}\text { The research methodology in a journal article will describe the methods used and will not include } \\
\text { extensive discussion of the research approach and philosophy found in a dissertation. }\end{array}$ \\
\hline Research findings and analysis & $\begin{array}{l}\text { The research findings and analysis in a journal article will provide the main findings and analysis of } \\
\text { the research and will not report all the results as commonly found in a dissertation. }\end{array}$ \\
\hline Discussion & The discussion section in a dissertation will be longer than in a journal manuscript submission. \\
\hline References & Only references cited in the text will be included in the journal article reference list. \\
\hline Appendices & Space and content requirements will limit the use of appendices in journal articles.
\end{tabular}

TABLE 7: Trimming the length.

\begin{tabular}{ll}
\hline Aspect & Reason for trimming \\
\hline Research questions & If the dissertation covers several distinct research questions, narrow the focus. \\
Results & Try to bring results under control. \\
Presentation & Try to avoid the common presentation pitfalls of many novice writers. \\
Conventions & Certain conventions in dissertations do not lend themselves to the presentation format for journals. \\
References & Be selective in the references that are reported in the literature review. \\
Writing style & Strive for clarity, delete extraneous words, avoid excessive reporting and repetition, be explicit, use the \\
Interpretation of data & active voice, and use correct grammar. \\
Careful conversion & Be careful not to overinterpret the data. Show restraint in forming the conclusions. \\
\hline
\end{tabular}

Sources: Cone and Foster [2], Calfee and Valencia [8], and Carver [9].

accept subject to major revision, or reject. The reasons for the decision will be given, and it is important to take these into consideration to amend the paper to satisfy the editor and reviewers or if rejected to make changes in order to send the paper to another journal. The paper may be returned to the author(s) two, three, or four times for amendments. Responsibility for the preparation and correction of the work will fall on the author(s), and this usually involves tight deadlines. Publications in high-ranking journals can take at least two years so that a publication plan can be helpful in terms of submitting and publishing papers in a number of journals. In terms of the current REF, since the deadline is November 2013, a two-year plan is appropriate.

\section{Contents: Format and Review}

The contents of an article will follow the format of the journal, and although this will vary, it is possible to identify a typical format (Table 9). This includes an abstract, introduction (including the purpose of the paper), literature review (with a conceptual framework), research methods (design, sampling strategy, data collection techniques, and analysis), results, discussion (interpretation or implications of results), conclusion, and references.
TABLE 8: Dissertation to publication.

\begin{tabular}{ll}
\hline Stages & Activity \\
\hline Stage one & Plan for converting the dissertation to article \\
Stage two & Starting the article \\
Stage three & Advancing the argument \\
Stage four & Selecting a journal \\
Stage five & Reviewing the literature \\
Stage six & Strengthening the structure \\
Stage seven & Presenting the evidence \\
Stage eight & Opening and concluding the article \\
Stage nine & Feedback \\
Stage ten & Editing \\
Stage eleven & Wrapping up \\
Stage twelve & Sending the article \\
Stage thirteen & Review from journal \\
Stage fourteen & Responding to journal review \\
Stage fifteen & Acceptance and publication \\
\hline
\end{tabular}

Source: Belcher [3].

When an article is considered, the reviewers' comments will be made in relation to the journal review format (Table 10). These will include those regarding the originality 
TABLE 9: Typical format for a journal article manuscript.

Abstract
Introduction (including purpose of paper)
Literature review (with conceptual theoretical framework)
Methods
$\quad$ (i) Design
$\quad$ (ii) Setting and sampling strategy
$\quad$ (iii) Data collection techniques
(iv) Analysis
Results
Discussion (including interpretation or implications of results)
Conclusion
References

Source: Bowen [4].

of the paper set out in the introduction concerning the purpose, the relationship to the literature, the methodology, results, discussion, and conclusions.

\section{Seven Rules}

There are seven lessons enunciated by Bowen [4] for writing, submitting, and revising papers for publication, and these are reported as rules to be followed in Table 11 below.

Rule 1 (a summary of the dissertation will not suffice). Differences between journal articles and dissertations involve content, format, and length. A dissertation can be more than 100 pages if it has a length of 20,000 words. It will also usually have a six-chapter structure with an introduction to the research problem as the first chapter, a literature review as the second, the third research methodology, chapter four findings, five analysis, and six conclusion and recommendations. A journal article will be from 15 to 25 double-spaced pages and between 4,000 and 7,000 words in length. Consequently there is a need to reduce the length of a dissertation so that it is appropriate for submission as a journal article to an editor. A summary of the dissertation will not suffice.

Manuscripts that are appropriate to the scope and progress the goals of a journal will be welcomed by editors. There are four main types of journal article which sometimes overlap. These include articles which report original research using systematic data collection and analytical methods, review articles which critically review literature, methodological articles which describe innovative research methods, designs, or paradigms, and theoretical articles which present original theory or assess existing theory. Articles that can be written from a dissertation include critical literature reviews, methodological papers, research findings or results articles, and policy, practice, and research implications papers.

Rule 2 (thick description is often necessary). With qualitative research papers there will be "thick" description of the context, methodology, and the phenomena. Whereas "thin" description lacks context, and meaning "thick" description provides balance of interpretation and analysis [11]. By providing thick description it shows that the paper is based on research that is rigorous and thorough with an appropriate methodology. Reviewers will like to see explanation of the rationale of the research approach and the theoretical underpinning of the method of data collection.

Rule 3 (advantages of collaboration with colleagues). There are a number of advantages of collaborating with colleagues who have previous expertise and experience publishing articles, and through this knowledge it is possible to avoid difficulties in the process of papers being accepted. An inexperienced author can ask a more experienced colleague to provide a review of an article, and a critical eye can be cast on the manuscript in terms of its quality and relevance to a journal. By doing this early reviews of a manuscript can be given, and help can be provided to manuscript review and the publications process. Critical feedback can shorten the time to submit and publish.

Collaboration on papers usually leads to the coauthorship of articles, and there is the need to be clear on the roles of coauthors and their position in the author list. It has been recommended by Fine and Kurdek [12] that authorship credit and order needs to be based on scholarly ability and contribution.

Rule 4 (it is essential to adhere to guidelines and deadlines). Guidelines for authors are provided by editors and publishers and cover style, format, and length of article. Details of the aim and scope of the journal, editorship and policy, types of manuscripts, and procedures for submission and review are usually provided on journal websites. Journals usually require an article to have a particular structure and to use the Harvard referencing system. There is a need to follow manuscript preparation and submission guidelines carefully. This is particularly important since when an article follows the style of a journal correctly, the reviewers and editor can concentrate on the content and provide recommendations more easily for the manuscript to be considered for publication.

Rule 5 ("revise and resubmit" is common). It is advisable to cite articles from the journal to which one is submitting a paper. This will ensure that the editor is aware that the article progresses research in the journal, and there will be a chance that reviewers' articles will be cited which will make the manuscript attractive for consideration. An author should be prepared to revise and resubmit a paper since a first version will probably not be enough, and papers are rarely accepted in the form they have been submitted. Quite often a paper may go through two revision stages.

With the blind peer-review process (anonymous authors and reviewers) all papers have the same chance of acceptance or rejection, and each paper will be assessed on its quality, merit, and appropriateness for publication in the journal. Usually constructive criticism will be provided by reviewers and editors, and this will provide useful revision and improvement suggestions to help publication [13]. It is important to read reviewers' comments carefully and 
TABLE 10: Typical manuscript review format.

Manuscript review

(1) Originality: does the paper contain new and significant information adequate to justify publication?

(2) Relationship to literature: does the paper demonstrate an adequate understanding of the relevant literature in the field and cite an appropriate range of literature sources? Is any significant work ignored?

(3) Methodology: is the paper's argument built on appropriate base theory, concepts, or other ideas? Has the research or equivalent intellectual work on which the paper is based been well designed? Are the methods employed appropriate?

(4) Results: are results presented clearly and analysed appropriately? Do the conclusions adequately tie together the other elements of the paper?

(5) Implications for research, practice, and/or society: does the paper identify clearly any implications for research, practice and/or society? Does the paper bridge the gap between theory and practice? How can the research be used in practice (economic and commercial impact), in teaching, to influence public policy, in research (contributing to the body of knowledge)? What is the impact on society (influencing public attitudes and affecting quality of life)? Are these implications consistent with the findings and conclusions of the paper?

(6) Quality of communication: does the paper clearly express its case, measured against the technical language of the field and the expected knowledge of the journal's readership? Has attention been paid to the clarity of expression and readability, such as sentence structure, jargon use, acronyms, and so forth.

Recommendation

(i) Accept

(ii) Minor revision

(iii) Major revision

(iv) Reject

Would you be willing to review a revision of this manuscript?

(i) Yes

(ii) No

Comments

Confidential to the coeditor

Comments to the author

Source: Emerald [10] ScholarOne Manuscripts, http://mc.manuscriptcentral.com/.

TABLE 11: Seven rules.

\begin{tabular}{ll}
\hline Rules & Specific rule \\
\hline 1 & A summary of the dissertation will not suffice. \\
2 & Thick description is often necessary. \\
3 & Advantages of collaboration with colleagues. \\
4 & It is essential to adhere to guidelines and deadlines. \\
5 & "Revise and resubmit" is common. \\
6 & Be careful of electronic journals. \\
7 & Patience and persistence will pay. \\
\hline
\end{tabular}

Source: Bowen [4].

respond sensibly. In terms of "revise and resubmit" it is necessary to consider the reviewers' comments on the manuscript and to itemise each point in numerical order and to provide page numbers where revisions have been made so with resubmission this information is clearly provided in the response document, e-mail, or letter which makes it easier for the editor and reviewers to confirm amendments made.

Rule 6 (be careful of electronic journals). Due to the fast growth in journals and online journals on the Internet and World Wide Web there is a need to be careful with these since they will not be as well rated as a hard copy/electronic journal. There is a need for the selection of journals which involves determining which are appropriate and whether they have a rigorous peer-review process in terms of publication quality. To determine appropriateness it is helpful to consider the journal contents and articles; whether the journal has a track record of publishing quality articles by reputable authors; if the manuscript will "fit" into the journal and to prepare submission according to author guidelines. Since there is no guarantee that a submission will be forwarded by an editor to reviewers, it is sensible to keep a shortlist of alternative journals which will help to reduce the time taken to publish a paper. There is a need to match the paper topic and the topics that are of interest to the journal and to note that rated journals have high rejection rates. Therefore submit good quality articles to high-ranked journals, and although the process may take a long time it is worth persevering.

Rule 7 (in the end patience and persistence will pay). Journal publication processes can be long and time consuming since articles may have two or more revisions which can extend publication by five or six months. On average the time taken to receive an editorial response after submission is four months resulting in more than 12 months from submission to publication [4]. There is a need to develop a "rapport" 


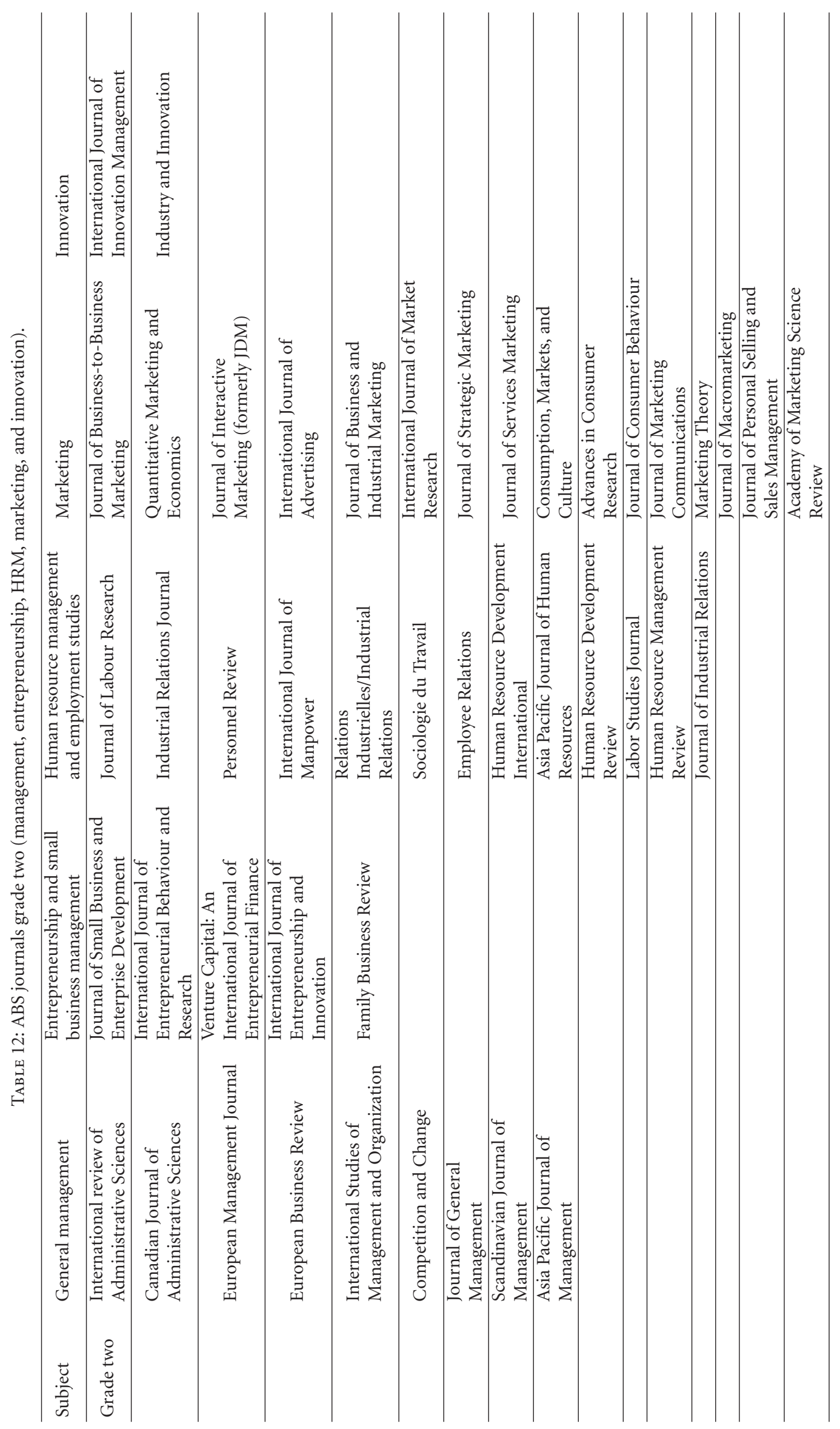




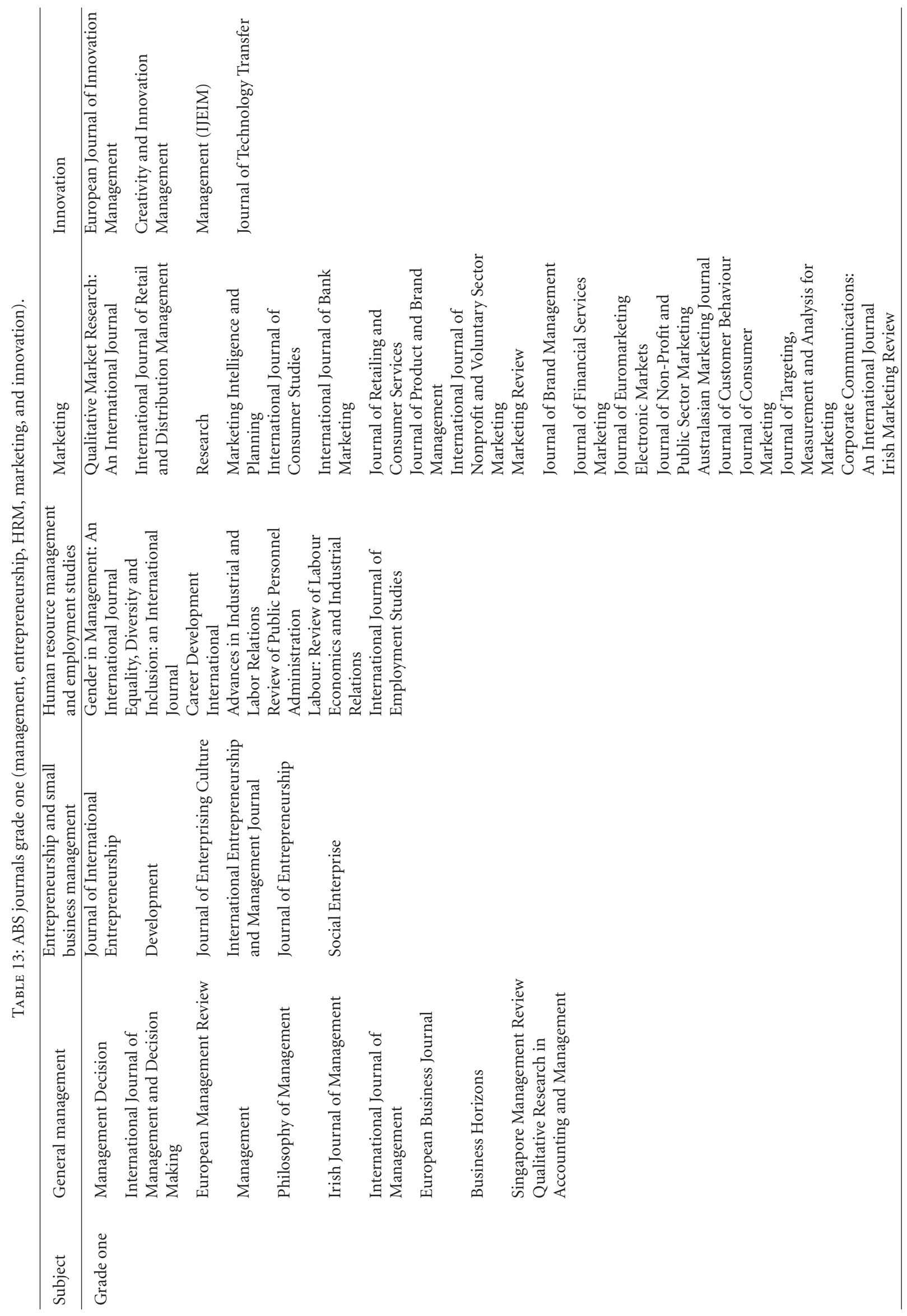


TABLE 14: REF personal publication programme.

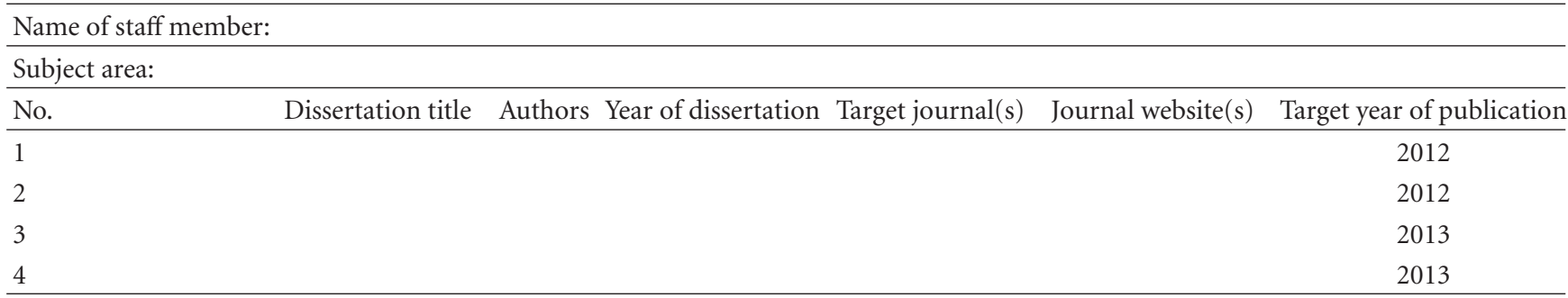

TABLE 15: Dissertation to journal pro forma (from 2012 to 2013).

\begin{tabular}{|c|c|}
\hline Details & Planning stages: one to fourteen \\
\hline Name of member of staff & \multirow{9}{*}{ Week 1: stages $1,2,3$, and 4} \\
\hline Subject area & \\
\hline Dissertation title & \\
\hline Authors & \\
\hline Supervisor & \\
\hline Masters' student & \\
\hline 2nd academic staff author & \\
\hline Target journal & \\
\hline Web site & \\
\hline Writing the draft & \multirow{7}{*}{ Week 2: stages $5,6,7$, and 8} \\
\hline Introduction & \\
\hline Literature review & \\
\hline Methods & \\
\hline $\begin{array}{l}\text { Results } \\
\text { Discussion }\end{array}$ & \\
\hline Conclusion & \\
\hline References & \\
\hline First draft & Week 3: stage 9 \\
\hline Editing & Week 4: stage 10 \\
\hline Submission of final draft to journal & Week 5: stages 11,12 \\
\hline Review from journal & Weeks 6-14: stage 13 \\
\hline Responding to journal review & Weeks 15-22: stage 14 \\
\hline Acceptance and publication & Weeks 23-26: stage 15 \\
\hline
\end{tabular}

with the editor of a journal. It is important to be patient and persistent since in the higher education environment of the early 21 st century, and with the need for submission to REF 2014 , there is still the mantra of "publish or perish."

\section{Conclusions: Publication "Tool Kit"}

This paper provides a systematic approach to develop a Masters dissertation into a journal article through a stepby-step procedure that can be learnt and repeated. This is encapsulated in a "toolkit" for use by academics to enable them to convert a good dissertation into a ranked journal article. Important elements to progress a dissertation into a journal article are considered, and these include the quality of the dissertation, the authorship, how dissertations differ from journal articles, reframing for publication, turning the dissertation into a publication, contents, seven rules, and conclusions. Pertinent approaches, processes, lessons, and guidance have been noted and analysed. Through distillation of relevant material, to enable efficient conversion of dissertations into journal articles, appropriate procedures and conclusions are provided in the publication "tool kit." This composes three instruments which are the ABS journals selection tables (grades 2 and 1), the personal publication programme and the dissertation to journal pro forma:

(i) ABS journals grade two (management, entrepreneurship, HRM, marketing, and innovation)_-Table 12, and

(ii) ABS journals grade one (management, entrepreneurship, HRM, marketing, and innovation)_-Table 13, and

(iii) REF personal publication programme-Table 14, and 
(iv) dissertation to journal pro forma (2012 to 2013)Table 15.

The three instruments are provided as tables in the appendices to this paper.

The seven rules presented relate to working relationships, the publication process, and article style and content [4]. Turning a dissertation into a journal paper quality is of greater importance than quantity, and the process should not involve a summary of the dissertation. It is also necessary to avoid verbosity and wordiness and to provide "thick" description with regard to phenomena. Nascent authors benefit from working and collaborating with experienced well-published academics, and through this the publication path can be navigated. Publication guidelines need to be adhered to, and both positive and negative paper reviews should be responded to in full. By following the peer-review process diligently and adopting best practice procedures good quality papers can be written which are merited by publication in internationally recognised journals.

\section{Appendix}

See Tables 12, 13, 14, and 15 .

\section{Disclaimer}

The views expressed in this paper are those of the authors.

\section{References}

[1] C. Lambert, "Revising the Dissertation for Journal Publication, Technical Communication Quarterly, Guidelines," 2011.

[2] J. D. Cone and S. L. Foster, Dissertations and Theses from Start to Finish: Psychology and Related Fields, American Psychological Association, Washington, DC, USA, 2nd edition, 2006.

[3] W. L. Belcher, Writing Your Journal Article in Twelve Weeks: A Guide to Academic Publishing Success, Sage, Thousand Oaks, Calif, USA, 2009.

[4] G. A. Bowen, "From qualitative dissertation to quality articles: seven lessons learned," The Qualitative Report, vol. 15, no. 4, pp. 864-879, 2010.

[5] American Psychological Association (APA), "Calfee and Valencia's Guide to Preparing Manuscripts for Journal Publication," 2011, http://www.apa.org/journals/.

[6] American Psychological Association (APA), "Preparing Manuscripts for Publication in Psychology Journals: A Guide for New Authors," 2011, http://www.apa.org/journals/.

[7] A. G. H. Johnson and B. C. Thomas, Getting Published: A Guide for University Staff and Research Students, University of Glamorgan, Pontypridd, UK, 1997.

[8] R. C. Calfee and R. R. Valencia, APA Guide to Preparing Manuscripts for Journal Publication, American Psychological Association, Washington, DC, USA, 2007.

[9] R. P. Carver, Writing a Publishable Research Report in Education, Psychology, and Related Disciplines, Charles Thomas, Springfield, Ill, USA, 1984.

[10] Emerald, "ScholarOne Manuscripts," 2012, http://mc.manuscriptcentral.com/.

[11] M. Q. Patton, Qualitative Research and Evaluation Methods, Sage, Thousand Oaks, Calif, USA, 3rd edition, 2001.
[12] M. A. Fine and L. A. Kurdek, "Reflections on determining authorship credit and authorship order on faculty-student collaborations," American Psychologist, vol. 48, no. 11, pp. 1141-1147, 1993.

[13] G. A. Bowen, "Preparing a qualitative research-based dissertation: lessons learned," The Qualitative Report, vol. 10, no. 2, pp. 208-222, 2005. 


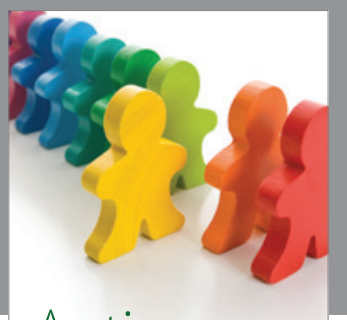

Autism

Research and Treatment
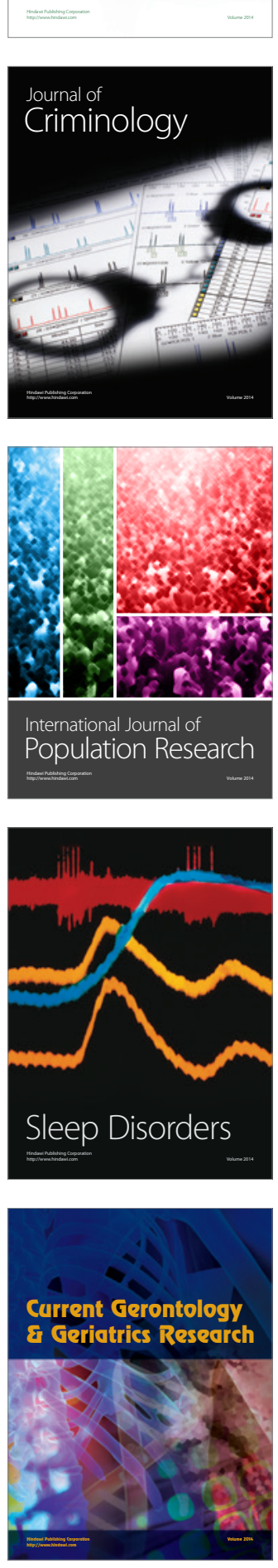
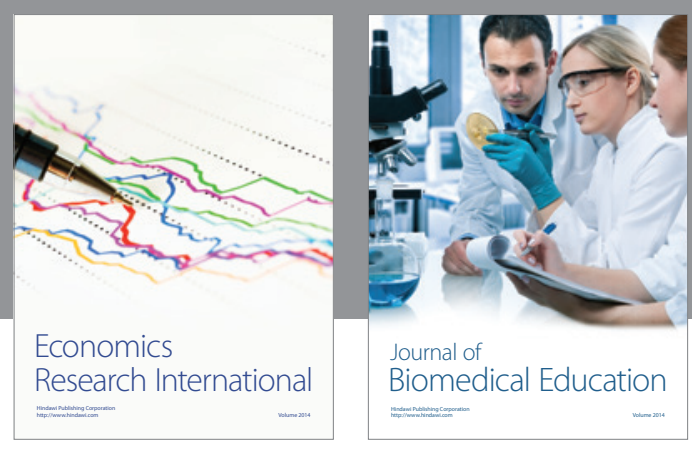

Journal of

Biomedical Education

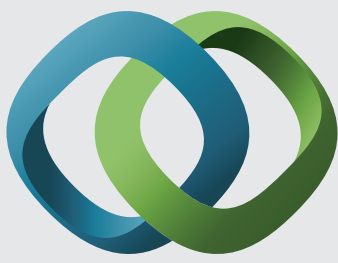

\section{Hindawi}

Submit your manuscripts at

http://www.hindawi.com
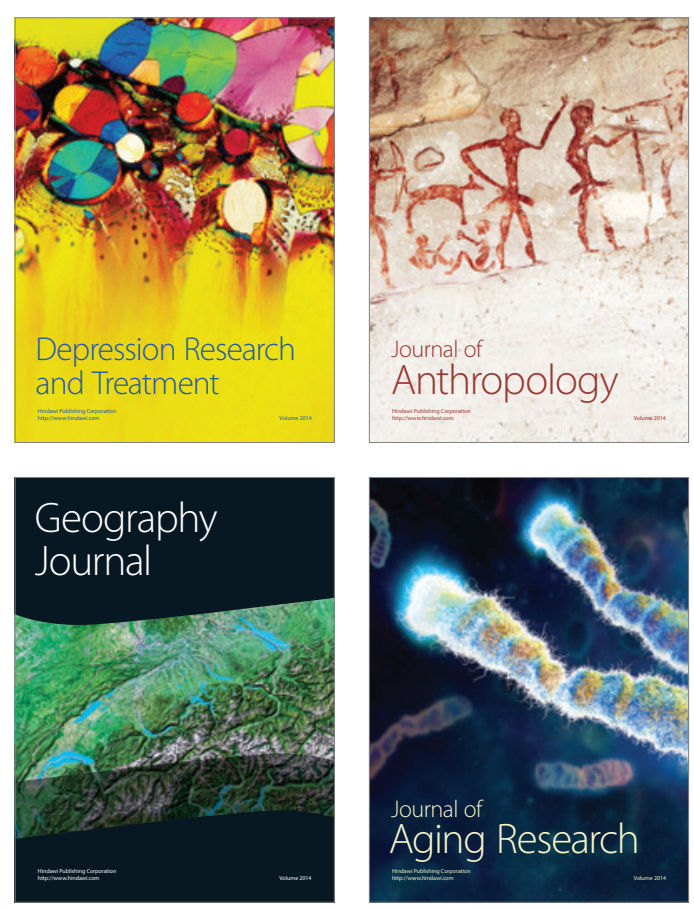

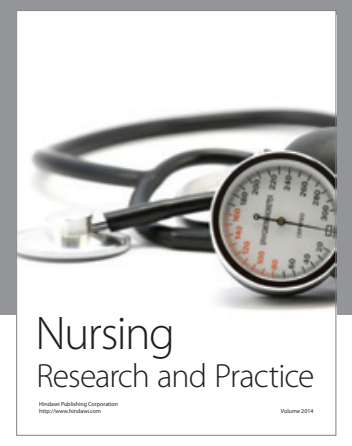

Nursing

Research and Practice

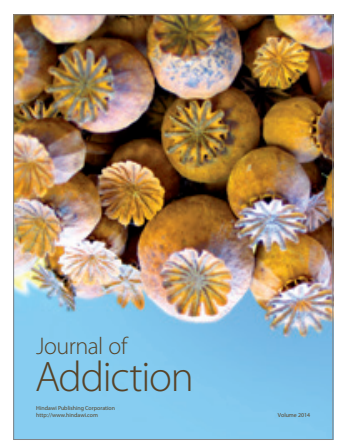

Child Development

Research

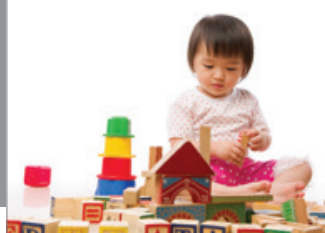

迥
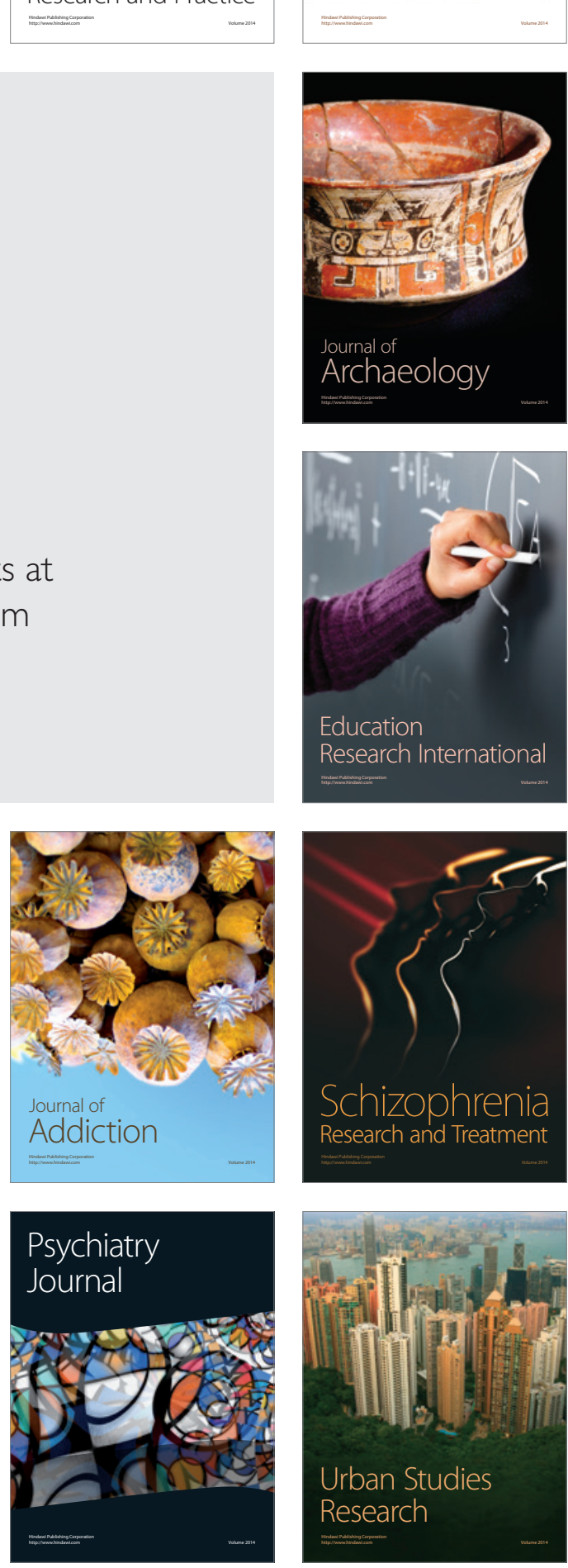